\title{
Assessment of Methanol Crossover Through a Nafion Membrane Using a Platinum Microdisc Electrode
}

\author{
Minoru UMEDA, ${ }^{\text {* }}$ Yoshiaki HaTAKEYAMA, ${ }^{\mathrm{b}}$ Mohamed MOHAMEDI, \\ and Isamu UCHIDA ${ }^{b}$
}

\begin{abstract}
a Department of Chemistry, Faculty of Engineering, Nagaoka University of Technology (Kamitomioka 1603-1, Nagaoka, Niigata 940-2188, Japan)

bepartment of Applied Chemistry, Graduate School of Engineering, Tohoku University (Aramaki-Aoba 07, Aoba-ku, Sendai 980-8579, Japan)

'Present address: Advanced Research Institute for Science and Engineering, Waseda University, Shillman Hall\#702 (Shinjuku-ku, Okubo 3-4-19, Tokyo 169-8555, Japan)
\end{abstract}

Received August 20, 2003 ; Accepted October 24, 2003

\begin{abstract}
In direct methanol fuel cells, methanol crossover causes not only a loss of methanol fuel but also a reduction of the open circuit voltage. We have developed a rapid evaluation of methanol crossover through a proton exchange membrane by utilizing a Pt-microdisc electrode. The equipment consisting of a Nafion film sandwiched by a pair of PTFE sheets was put into a set of glass cells. The reservoir cell was filled with $0.5 \mathrm{M} \mathrm{H}_{2} \mathrm{SO}_{4}$, which contains methanol in various concentrations, and the opposite receiver cell was filled with $20 \mathrm{ml}$ of $0.5 \mathrm{M} \mathrm{H}_{2} \mathrm{SO}_{4}$, which also included the Pt-microdisc electrode, a counter electrode and a reference electrode. By making contact of the Pt electrode with the membrane, methanol-oxidation current-potential curves were measured to evaluate the crossover. The crossover on the Nafion surface was assessed to be $60 \%$ of the reservoir methanol concentration. Consequently, the developed equipment quickly and successfully evaluates the methanol crossover.
\end{abstract}

Key Words : Direct Methanol Fuel Cell, Proton Exchange Membrane, Methanol Crossover, Microdisc Electrode, Methanol Electrooxidation

\section{Introduction}

Liquid feed direct methanol fuel cells (DMFCs) are one of the most promising electric-power generator as a small size and a lightweight, since it directly oxidizes the methanol fuel at an anode without the need of a reformer subsystem. ${ }^{1,2)}$ For practical use, development of anode electrocatalysts and suppression of methanol crossover are requisite to improve the cell performance.

One problem to tackle is methanol diffusion from anode to the cathode side, across the polymer electrolyte membrane (methanol crossover). This phenomenon yields to loss of methanol fuel and reduces the open circuit voltage. ${ }^{3)}$ With regard to the measurements on proton exchange membrane (PEM), (i) $\mathrm{CO}_{2}$ trace by IR study and gravimetric analysis, ${ }^{4,5)}$ (ii) electrochemical method, ${ }^{6,7)}$ (iii) gas chromatography study ${ }^{8,9)}$ and (iv) electrochemical methods combined with chromatography $^{10)}$ or mass spectroscopy ${ }^{11)}$ are employed for the membrane electrode assembly, so far. Nevertheless, a concise and convenient technique for evaluating the methanol crossover at the membrane alone has not been proposed yet.

Ultramicroelectrodes are a much attractive electroanalytical tools based on their small size and small current features, which ordinary-size electrodes are incapable for example in high resistivity medium and/or for a small target. ${ }^{12,13)}$ We have demonstrated that the use of ultramicroelectrodes are valuable for analyzing electrode reac- tion mechanisms, ${ }^{1 i-16 j}$ evaluation of electrocatalysts, ${ }^{1 i .18}$ and ionic conductivity measurement of proton exchange membrane $(\mathrm{PEM})^{19,20)}$ for the DMFCs and PEM fuel cells.

In the present study, we applied a microdisc electrode for the assessment of methanol crossover through the PEM. This report describes experimental results of the methanol crossover measurement with a major focus on the microelectrode positioning, especially in contact to the PEM surface.

\section{Experimental}

A microdisc electrode for the methanol crossover detection was prepared as follows. A Pt wire of $20 \mu \mathrm{m}$ in diameter connected to a $\mathrm{Cu}$ lead wire was inserted into a glass tube of $1.2 \mathrm{~mm}$-outer diameter to inside of the tip. Subsequently, the tip of the tube was heat-sealed, cut off and then polished to a mirror finish.

Nafion 117 (Aldrich: $178 \mu \mathrm{m}$ thick) was employed as proton exchange membrane being cut to a size of $1 \mathrm{~cm}$ $\times 1 \mathrm{~cm}$. Prior to the methanol crossover measurements, the Nafion film was successively boiled in $0.3 \% \mathrm{H}_{2} \mathrm{O}_{2}$, Milli-Q water, $0.5 \mathrm{M} \mathrm{H}_{2} \mathrm{SO}_{4}$ and again Milli-Q water each for 1 hour. ${ }^{21}$

The Nafion film was sandwiched between a pair of 2 mm-thick PTFE sheets both having a $5 \mathrm{~mm}$-diameter hole and put into a set of glass cells, all held using a cramp at the cell flanges. The experimental setup is 


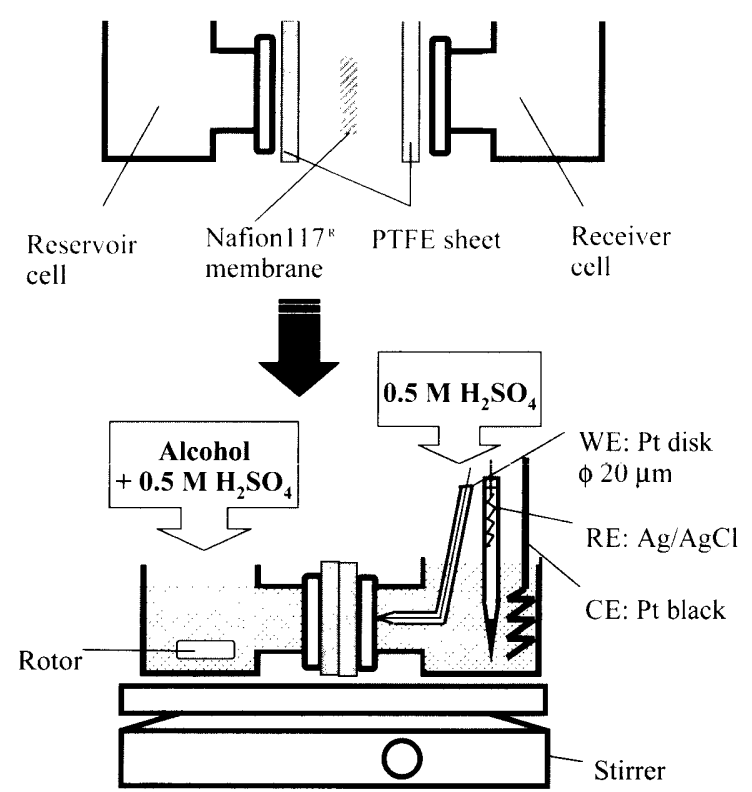

Fig. 1 Schematic of the measurement system for methanol crossover.

schematically shown in Fig. 1. For the crossover measurement, the left-hand methanol reservoir cell was filled with $20 \mathrm{ml}$ of $0.5 \mathrm{M} \mathrm{H}_{2} \mathrm{SO}_{4}$ that contains methanol of various concentrations, and the right-hand methanol receiver cell was filled with $20 \mathrm{ml}$ of $0.5 \mathrm{M} \mathrm{H}_{2} \mathrm{SO}_{4}$. The aboveprepared microdisc electrode was settled in the receiver cell by using a micro-manipulator (Shimadzu: MMS-77S) to contact with the Nafion film surface, together with a platinized platinum wire as a counter electrode and an $\mathrm{Ag} / \mathrm{AgCl}$ reference electrode. All potentials reported in this article are with respect to the relative hydrogen electrode (RHE).

The procedure for assessing the methanol crossover is as follows. The cell system involving a rotor in the reservoir cell was placed on a magnetic stirrer. Each cell was filled with the above-mentioned deaerated solution, then being bubbled by nitrogen gas. During the bubbling for 5 minutes, the reservoir cell was stirred by the magnetic stirrer. Subsequently, the bubbling and the stirring were stopped until a series of crossover measurement was finished. The methanol crossover was detected by the Pt microdisc electrode by means of linear sweep voltammetry using a potentiostat (Hokuto Denko: HA-150). All the measurements were carried out at $25 \pm 2^{\circ} \mathrm{C}$.

\section{Results and Discussion}

In the experimental setup seen in Fig. 1, the methanol that passed through the Nafion film from the reservoir cell to the receiver cell is detected at the Pt-microdisc electrode as a methanol oxidation current. Before that, for the purpose of calibration, linear sweep voltammograms were recorded by using the set of the three electrodes in the reservoir cell resulting in current-potential curves shown in Fig. 2. In the figure, each voltammogram measured by changing the methanol concentration shows a current peak related to methanol oxidation at the Pt electrode. A relationship between the methanol concentration and the peak current density is plotted in

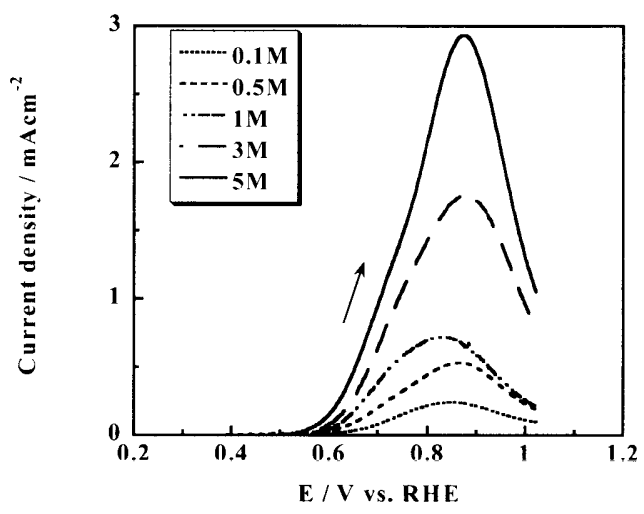

Fig. 2 Linear sweep voltammograms of methanol oxidation at $\mathrm{Pt}$ microdisc electrode with varying methanol concentration in $0.5 \mathrm{M} \mathrm{H}_{2} \mathrm{SO}_{4}$ for calibration. Scan rate: $10 \mathrm{mVs}^{-1}$.

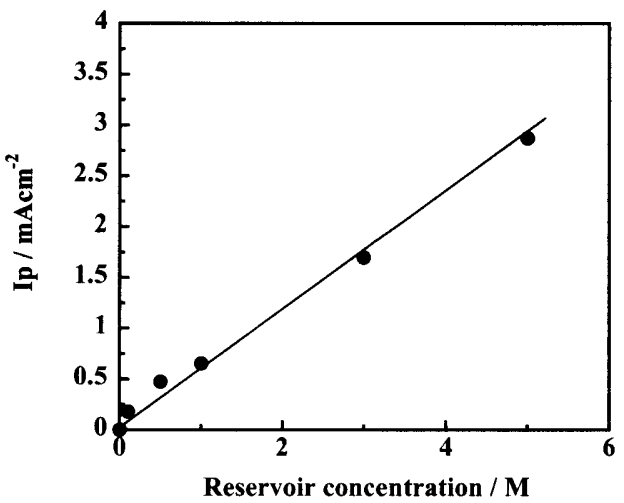

Fig. 3 Anodic peak current vs. concentration plot of methanol oxidation as a calibration curve. Plots are taken from Fig. 2.

Fig. 3. The magnitude of the current density is obtained by subtracting the background current density from methanol oxidation. A good linear relation is obtained, indicating that quantification of the methanol crossover can be assessed by the voltammetry measurement. Then, by using the calibration line and anodic peak currents recorded in the receiver cell, methanol crossover concentration at the Nafion film is measured by the setup shown in Fig. 1, based on the experimental procedure described in the above section.

Figure 4 shows experimental results of methanol concentration measured at the Nafion surface in the receiver side as a function of methanol concentration in the reservoir cell. Since the objective is not a membrane electrode assembly (MEA) but a Nafion, the detected methanol is based solely on a diffusion phenomenon. Hence, methanol crossover, $J$, is expressed as, ${ }^{22)}$

$$
J=D\left(C_{\mathrm{F}}-C_{\mathrm{N}}\right) / d
$$

in which, $D$ is a diffusion coefficient, $d$ is a thickness of Nafion film, $C_{\mathrm{F}}$ and $C_{\mathrm{N}}$ mean methanol concentrations in the reservoir cell and at the Nafion surface in the receiver side, respectively. However, when the microelectrode is placed $100 \mu \mathrm{m}$ from the Nafion surface, no methanol oxidation current was detected, which means the methanol passed through the Nafion immediately dif- 


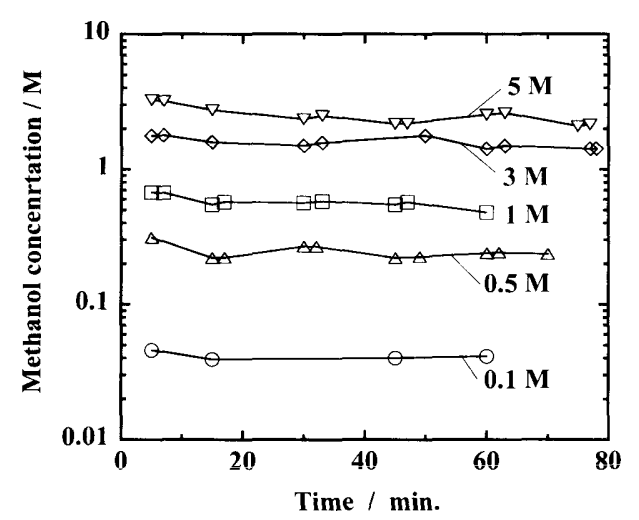

Fig. 4 Methanol crossover concentration at the Nafion surface in the receiver side as a function of methanol concentration in the reservoir cell.

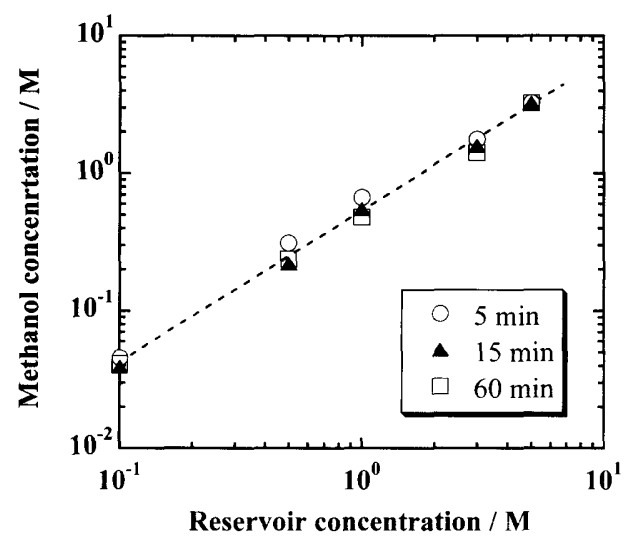

Fig. 5 Methanol concentration in the reservoir cell vs. Nafion surface in the receiver side. Plots are taken from Fig. 4.

fuses to dilute in the receiver solution. This signifies that the methanol oxidation current measured at the Ptmicrodisc electrode which was kept in contact only with the Nafion film provides $C_{\mathrm{N}}$. The graphs in Fig. 4 denote that the methanol concentration measured at the membrane surface is almost time independent. According to the data, methanol concentration at the Nafion surface as a result of crossover is $3 \mathrm{M}$ when the reservoir concentration is $5 \mathrm{M}$, which implies the crossover degree is $60 \%$. In the case of $1 \mathrm{M}$ reservoir concentration, the magnitude of crossover is known to be $50-60 \%$. Based on the report that the methanol:water molecular ratio in the Nafion membrane when in contact with $1 \mathrm{M}$ methanol solution is $0.4: 20.7,{ }^{23)}$ Qi et al. estimated the methanol concentration in the membrane is about $0.76 \mathrm{M} .^{24)}$ Since the methanol crossover measured in this equipment is well in accordance with those previously reported, it could be said that the developed technique can evaluate the methanol concentration at the Nafion surface as a result of crossover concisely and conveniently. In addition, about $50 \%$ methanol fuel is reported to be lost by the crossover for a single-cell operation. ${ }^{25)} \mathrm{A}$ small decrease of methanol concentration in Fig. 4 seems to be due to the crossover.

Figure 5 shows the relationship between methanol concentration in the reservoir cell and crossover concen- tration on Nafion surface in the receiver side. The slope of the logarithmic plots is 1.07 , which denotes that the crossover occurs in proportion to methanol concentration. Based on these findings, it can be known that employing a dilute fuel suppress the crossover as expected from eq. (1).

Consequently, methanol crossover through the Nafion membrane was successfully assessed by the microdiscelectrode-based equipment. We are planning to investigate permeation in terms of time-dependent methanol concentration in the receiver cell in the future.

\section{Conclusions}

We have developed a rapid evaluation of methanol crossover through a proton exchange membrane by utilizing a Pt-microdisc electrode. The equipment consisting of a Nafion film sandwiched by a pair of PTFE sheets was put into a set of glass cells. The reservoir cell was filled with $0.5 \mathrm{M} \mathrm{H}_{2} \mathrm{SO}_{4}$ containing methanol in various concentrations, and the opposite receiver cell was filled with $20 \mathrm{ml}$ of $0.5 \mathrm{M} \mathrm{H}_{2} \mathrm{SO}_{4}$, which also included the Ptmicrodisc electrode, a counter electrode and a reference electrode. By contacting the Pt electrode with the membrane, methanol-oxidation current-potential curves were measured to evaluate the crossover. The crossover on the Nafion surface was assessed to be $60 \%$ of the reservoir methanol concentration. As a result, the developed equipment concisely and successfully evaluates the crossover.

\section{Acknowledgements}

This work was supported by Grant-in-Aids for Scientific Research (B) (No. 14350450) from The Ministry of Education, Culture, Sports, Science and Technology (MEXT), Japan. The present work was also financially supported by the research and development of polymer electrolyte fuel cell from the New Energy and Industrial Technology Development Organization (NEDO), Japan.

\section{References}

1) J. Larminie and A. Dicks, Fuel Cell Systems Explained, Wiley, Chichester (2000).

2) Fuel Cell Handbook, 6th ed., (Eds. DOE/NETL), EG\&G Technical Services, Morgantown, Chap.3 (2002).

3) C. Lamy, A. Lima, V. LeRhun, F. Delime, C. Coutanceau, and J.-M. Léger, J. Power Sources, 105, 283 (2002).

4) S. R. Narayanan, H. Frank, B. Jeffries-Nakamura, M. Smart, W. Chun, and G. Halpert, Proton Conducting Membrane Fuel Cells I (Eds. S. Gottesfeld, G. Halpert, and A. Landgrebe), PV 95-23, p.278, The Electrochemical Society Proceedings Series, Pennington (1995).

5) R. Jiang and D. Chu, Electrochem. Solid-State Lett., 5, A 156 (2002).

6) X. Ren, T. E. Springer, and S. Gottesfeld, J. Electrochem. Soc., 147, 92 (2000).

7) N. Munichandraiah, K. McGrath, G. K. S. Prakash, R. Aniszfeld, and G. A. Olah, J. Power Sources, 117, 98 (2003).

8) S. Hikita, K. Yamane, and Y. Nakajima, JSAE Review, 22, 151 (2001).

9) M. Walker, K.-M. Baumgärtner, M. Kaiser, J. Kerres, A. 
Ullrich, and E. Räuchle, J. Appl. Polym. Sci., 74, 67 (1999).

10) B. Gurau and E. S. Smotkin, J. Power Sources, 112, 339 (2002).

11) A. Küver and K. Potje-Kamloth, Electrochim. Acta, 43, 2527 (1998).

12) M. Fleischmann, S. Pons, D. Robinson, and P. P. Schmidt, Ultramicroelectrodes, Datatech Systems, Morgantown (1987).

13) R. M. Wightman and D. O. Wipf, Electroanalytical Chemistry (Ed. A. J. Bard), Vol. 15, Marcel Dekker, New York, p. 267 (1988).

14) M. Umeda, K. Dokko, M. Mohamedi, T. Itoh, and I. Uchida, Chem. Lett. 2001, 508.

15) M. Umeda, M. Mohamedi, and I. Uchida, Langmuir, 17, $7970(2001)$

16) H. Ojima, M. Umeda, M. Mohamedi, and I. Uchida, Electroanalysis, 15, 1677 (2003).
17) M. Umeda, M. Kokubo, M. Mohamedi, and I. Uchida, Electrochim. Acta, 48, 1367 (2003).

18) C.-G. Lee, T. Itoh, M. Mohamedi, M. Umeda, I Uchida, and H.-C. Lim, Electrochemistry, 71, 549 (2003).

19) H. Ojima, M. Umeda, M. Mohamedi, and I. Uchida, Nippon Kagaku Kaishi (J. Chem. Soc. Jpn.) 501 (2001).

20) M. Umeda, H. Ojima, M. Mohamedi, and I. Uchida, J. Polym. Sci. Pt. B Pol. Phys. 40, 1103 (2002).

21) N. Yoshida, T. Ishisaki, A. Watanabe, and M. Yoshitake, Electrochim. Acta, 43, 3749 (1998).

22) N. Kamiya, Material Stage, 2(10), 32 (2003).

23) X. Ren, T. E. Springer, and S. Gottesfeld, J. Electrochem. Soc., 147, 92 (2000).

24) Z. Qi and A. Kaufman, J. Power Sources, 110, 177 (2002).

25) T. Hatanaka, Y. Morimoto, and K. Kawahara, Extended Abstracts of the 43rd Battery Symposium in Japan, The Committee of Battery Technology, The Electrochemical Society of Japan, p. 554 (2002). 